\title{
ESTUDO DE CASO DA FORMAÇÃO DE PROFESSORES NA LICENCIATURA EM QUÍMICA NA MODALIDADE EAD DA UFRN: REFLEXOS DA FORMAÇÃO ALICERÇADA NA RACIONALIDADE TÉCNICA DOS TUTORES
}

\author{
Fábio Adriano Santos da Silva | tfabioqui@yahoo.com.br \\ Professor na Universidade Estadual de Feira de Santana (UEFS), BA. Experiência na área de Educação e Ensino de Ciências, com ênfase \\ em Formação de Professores e Ensino de Química.
}

Elton Casado Fireman | eltonfireman@yahoo.com.br

Doutorado em Física pela Universidade Federal de São Carlos, SP. Professor adjunto do Centro de Educação da Universidade Federal de Alagoas, com estudos na área de ensino da Física e da Matemática.

\section{Resumo}

Pressupostos teóricos e documentos legais destacam que a formação de professores se alicerça no acúmulo de conhecimentos específicos e pedagógicos desvinculados entre si e das necessidades que atenderiam efetivamente à complexidade e desafios existentes nas salas de aula da educação básica, já que a formação se sustenta na racionalidade técnica. Defende-se, então, uma formação baseada na racionalidade prática, fundamentada na reflexão, onde se busca ultrapassar o simples acúmulo de conhecimentos a partir de um elo entre os conteúdos específicos, pedagógicos e a transposição didática dos diversos campos do conhecimento nas escolas de educação básica. À luz dessa proposta, pretende-se, com o presente trabalho, observar qual a posição da licenciatura em Química a Distância da UFRN, isto é, observar se o curso está voltado ao simples acúmulo de conhecimentos ou se busca meios de se adaptar às propostas de formação reflexiva, em que tomamos como referência as aulas experimentais desenvolvidas de 2008 a 2010. Assim, este levantamento foi feito a partir de dois pontos: 1 - leitura e análise das aulas experimentais propostas pelos professores; 2 - acompanhamento das aulas experimentais orientadas pelo tutor de laboratório. Os resultados desse acompanhamento demonstram que a experimentação na licenciatura em Química a Distância da UFRN e, como consequência, a formação que ela oferece, ainda estão ligadas à racionalidade técnica.

\section{Palavras-chave}

Formação de professor; Laboratório didático; Tutoria. 


\section{Case study in teacher formation at the} Chemistry degree course in distance learning modality at the federal university in Rio Grande do Norte: the reflection of the pedagogy with its foundation on technical rationality of mentors.

\section{Abstract}

Theoretical and legal documents point out that teacher education is rooted in the accumulation of expertise and teaching linked to the other and needs to effectively address the complexity and challenges that exist in classrooms of Basic Education, as education is grounded in rationality technique. It is argued, then, a training based on practical rationality, based on reflection, which seeks to go beyond the mere accumulation of knowledge from a specific link between the content, pedagogical and didactical approaches in other fields of knowledge in schools for Primary Education . In light of this proposal, intends, with this work, see what the position of Chemistry Degree Distance UFRN, ie see if the course is aimed at the mere accumulation of knowledge or is already looking for ways to adapt to training proposals reflective, where we control for the laboratory classes developed from 2008 to 2010 . Thus, this survey was made from two points: 1 - reading and analysis of practical classes offered by teachers, 2 - Monitoring of the practical lessons guided by tutor lab. The results of this monitoring show that experimentation with a degree in Chemistry UFRN distance, and consequently the training it offers, is still linked to technical rationality.

\section{Keywords}

Teacher training; teaching laboratory; tutoring.

\section{Introdução}

Segundo argumentam Shön (1992), Maldaner (2000), Mizukami (2002), entre outros, a formação de professores está alicerçada na racionalidade técnica, primando pelo acúmulo de conhecimentos teóricos, tanto específico quanto pedagógico, desvinculados entre si e das necessidades consideradas adequadas à atuação nas salas de aulas. Esses mesmos pesquisadores destacam que a formação deveria se firmar na racionalidade prática, primando pela reflexão, elo entre os conhecimentos específicos e pedagógicos e entre a teoria e a prática.

A partir dessas orientações, pretendemos com o presente trabalho observar qual a formação oferecida na licenciatura em Química a distância ofertada pela UFRN a partir das aulas experimentais. Para tanto, partimos da leitura e análise de dois segmentos que se complementam e cujo acompanhamento ocorreu no decorrer das aulas experimentais em 2008, 2009 e 2010, a saber:

- leitura das aulas experimentais propostas pelos professores das disciplinas experimentais;

- desenvolvimento dessas aulas pelos tutores de laboratório.

Acreditamos que essa etapa merece especial atenção por ser desenvolvida em momentos presenciais sob orientação de um tutor atento à proposta de organização das aulas experimentais pelos professores da UFRN.

Para iniciar os estudos, lançamos a hipótese de que as aulas experimentais desenvolvidas durante o curso de licenciatura em Química a distância da UFRN são reproduções de experimentos clássicos já consagrados e contemplados em várias literaturas específicas não direcionadas à formação de professores, sendo utilizadas como ferramentas para verificar $e$ comprovar o conteúdo teórico, em que não há a promoção de uma reflexão acerca do desenvolvimento de aulas experimentais contextualizadas nas escolas de educação básica, mas sim a contribuição de modo significativo para a formação de caráter técnico e fortalecimento dos conhecimentos específicos relacionados à Química.

Para buscar subsídios ao supracitado, tivemos como objetivos observar se: 
1. as aulas experimentais na graduação dão bases para o licenciando desenvolver, aperfeiçoar $e$ promover de modo didático aulas experimentais voltadas aos objetivos do conhecimento científico na educação básica;

2. as aulas experimentais na licenciatura contemplam apenas os conhecimentos específicos ou se promovem discussões acerca dos fenômenos naturais, dentro de um contexto social e ambiental;

3. as aulas experimentais fortalecem o conhecimento químico necessário à formação do professor dessa ciência;

4. as aulas experimentais fortalecem os conhecimentos pedagógicos que os licenciandos precisarão como professores de Química na educação básica.

Com a junção dessas questões, construímos os argumentos que deram base ao estudo. As linhas a seguir nortearam nossa busca e serviram de referência para nossos argumentos e considerações finais.

\section{Em busca da formação inicial reflexiva}

Conforme ensina Fávero (2005), a educação no Brasil se tornou um assunto de política pública e social ao deixar de ser monopólio da Igreja no final do século XVIII para se tornar função do Estado, em que, dentre os embates que acompanharam a evolução da legislação constitucional e educacional, estava a formação de professores.

Entretanto, Nóvoa (1995, p. 15) destaca que "a criação de instituições de formação é um projeto antigo, mas que só se realizará em pleno século XIX, graças à conjunção de interesses vários, nomeadamente do Estado e dos professores".

Zitkoski e Mello (2002) não apenas confirmam o expresso por Nóvoa como detalham alguns dos interesses por parte do Estado e dos professores. É dentro desse espírito que surgem as Escolas Normais e os primeiros professores primários.
Tanuri (2000) reforça essas afirmações ressaltando que, em junho de 1827, a Comissão de Instrução Pública apresenta o projeto de lei que, dentre outros assuntos, trata da criação de escolas de primeiras letras ou pedagogias. Tal projeto foi transformado em lei aos 15 dias de outubro de 1827.

Esta foi a primeira lei brasileira de educação que pressupunha a formação de docentes como incumbência do Estado.

Entretanto, Tanuri (2000) ressalta que apenas com o Ato Adicional de 21 de agosto 1834 a formação de docentes começou a ser efetivada nas províncias. A autora destaca que até a década de 1930 a formação docente era limitada às escolas normais. Eis que surgem em 1939 as primeiras abordagens acerca da formação docente em Nível Superior e adoção do modelo de formação denominado $3+1$.

Sob a perspectiva da formação $3+1$, os cursos de licenciatura seriam extensões dos cursos de bacharelado, em que se cursavam nos três primeiros anos as disciplinas de conhecimento específico, obtendo-se o título de bacharel, e depois se adquiria o grau de licenciado cursando um ano de disciplinas pedagógicas. É nesse momento que surge a dicotomia entre os conhecimentos específicos e pedagógicos e entre a teoria e a prática.

Apesar dos debates que surgiram, essa proposta perdurou até a promulgação da LDB 5.692/71, quando foi proposta a implantação dos cursos de licenciatura curta, para atuação nas escolas de $1^{\circ}$ grau (atual ensino fundamental), e licenciatura plena, para atuação no $2^{\circ}$ grau (atual ensino médio).

Contudo, mesmo com essas mudanças, os cursos de licenciatura continuavam sendo um reflexo do bacharelado, pois, entre outras razões, se fundamentavam fortemente nos conhecimentos específicos, destinavam de 20 a $25 \%$ da carga horária às disciplinas de conhecimento pedagógico, os conhecimentos específicos e pedagógicos estavam desvinculados entre si, as disciplinas voltadas à prática de ensino eram ofertadas no final do curso.

Sob esse norte, tem-se uma formação que se alicerça no acúmulo de conhecimento teórico para 
posterior aplicação, tanto de origem específica quanto pedagógica, desvinculada da prática, do cotidiano $e$ realidade das escolas e das salas de aula. Tal proposta é baseada no que Shön (1992), Maldaner (2000) e Mizukami (2002) denominam racionalidade técnica.

Em estudos feitos por Carvalho e Gil-Pérez (1995), Maldaner (2000) e Rosa (2004) destacam que à luz da formação de caráter meramente técnico não se tem conseguido alcançar uma formação que atenda às necessidades da realidade das salas de aulas, haja vista a falta de interação entre as disciplinas de conhecimentos específicos e as pedagógicas, a separação entre a teoria $e$ a prática $e$ a distância entre a universidade e as escolas.

Devido a isso, os licenciados, quando atuam nas escolas ministrando aulas, costumam deixar de lado os conhecimentos abordados na graduação e tomam como referência para a atuação $e$ formação do seu perfil docente os professores que passaram por suas vidas quando eram alunos, referendando o que é denominado formação ambiental.

Rosa (2004) tem essa visão ao afirmar que, ao término da formação inicial, os licenciados em geral acabam se apoiando em referências anteriores de professores que passaram pela sua vida escolar [...] e acabam se reportando ao seu tempo de aluno para tentar construir seu perfil docente.

Carvalho e Gil-Pérez (1995) destacam que a formação baseada no acúmulo de conhecimento $e$ mecanismos de transmissão destes apenas tem demonstrado insuficiência na preparação dos licenciados, sendo essa carência fruto de uma formação não reflexiva e baseada no senso comum sobre o que é ciência e qual a função desta na sociedade traçado à luz da formação ambiental.

Para superar a formação baseada na racionalidade técnica e na formação ambiental, Shön (1992), Maldaner (2000) e Mizukami (2002) destacam a relevância de uma formação alicerçada na racionalidade prática, que é reflexiva.

Mizukami (2002, p. 14-21) propõe que os cursos de formação devem se alicerçar numa racionalidade prática, norteados pela reflexão na formação, na qual sejam considerados a complexidade dos fenômenos educativos e os valores globais (éticos, políticos etc.) dos professores, norteados por uma reflexão na e sobre a ação, num processo contínuo de construção do professor.

Shön (1992), Carvalho e Gil-Pérez (1995), Maldaner (2000) são outros autores que também delineiam o tema.

Maldaner (2000), por exemplo, destaca que a reflexão sobre a ação e a reflexão na ação têm o potencial de tirar da rotina certos conhecimentos na ação e permitir a criação de novas soluções na prática, geralmente de grande relevância educativa para aquele grupo envolvido.

Carvalho e Gil-Pérez (1995, p. 31-40) defendem a formação alicerçada numa reflexão crítica que, concomitantemente, demonstre a insuficiência da formação ambiental e ofereça alternativas realmente viáveis de procedimentos didáticos.

Para Shön (1992), a formação alicerçada na reflexão ocorre quando se aceita que ela (a formação) ocorre na confusão e na incerteza. Sob esse matiz, o professor será levado a refletir sobre algo, e tal processo pode ocorrer em duas etapas: a primeira quando ele se defronta com a dúvida e gera uma ação; a segunda etapa ocorre quando ele reflete, a posteriori, sobre sua ação frente à dúvida. Quando ele se afasta para amadurecer e confrontar seus conhecimentos acerca da dúvida, em busca de respostas para tentar resolver o problema enfrentado, temos a reflexão sobre a ação. No entanto, para refletir a posteriori, o professor precisou antes se defrontar com a dúvida, isto é, com a incerteza que o levou à reflexão sobre a ação. Nesse ponto, no momento em que o professor se defronta com a dúvida, temos a denominada reflexão na ação.

A combinação da reflexão na ação com a reflexão sobre a ação num ir e vir reflexivo acerca do que gerou a incerteza leva a um practicum reflexivo, isto é, um aprender fazendo, e este, conforme Shön deve ser feito coletivamente e já na formação inicial, como forma de intervenção na formação alicerçada na racionalidade técnica. 
Mas os autores supracitados não estão sozinhos na busca de meios para superar a formação técnica $e$ ambiental. Também existem propostas de ordem legal. Três dessas recomendações legais se baseiam no proposto no Plano Nacional da Educação - PNE, segundo a Lei $n^{\circ}$ 10.172/01, no Parecer CNE/CP no 9/2001 e na Resolução CNE/CP n ${ }^{\circ} 1 / 2002$. No primeiro se destaca a necessidade de que na formação inicial é preciso superar a histórica dicotomia entre teoria e prática e o divórcio entre a formação pedagógica e a formação no campo dos conhecimentos específicos que serão trabalhados na sala de aula; no segundo se propôs o projeto de resolução que institui as Diretrizes Curriculares Nacionais para a Formação de Professores da educação básica em Nivel Superior fundamentado na ação-reflexão-ação; e no terceiro se instituem as diretrizes para a formação dos professores da educação básica.

\section{A formação inicial de professores de química}

Conforme Maldaner (2000) e Rosa (2004), uma queixa bastante comum entre os graduados da licenciatura em Química remete à insatisfação com a organização curricular do curso e ao distanciamento dele com as necessidades formativas para a atuação como professor, considerada satisfatória ${ }^{1}$ no Nível Médio. Atento a Maldaner (2000), a separação dos conhecimentos teórico e prático advém de uma visão positivista, técnica e neutra da ciência, fazendo com que a reprodução seja a característica inerente da formação.

Segundo discursa Maldaner (2000), a formação em fases estanques - na qual a formação inicial de professores é demasiadamente restrita, não problematizadora e não reflexiva - é a principal responsável pela crise nos cursos de licenciatura. E as licenciaturas em Química não são exceções à regra.

1 Entendemos como atuação satisfatória aquela em que os licenciados ministrem aulas nas escolas de educação básica que promovam a compreensão dos fenômenos naturais a partir de estudos que englobem a evolução dos conhecimentos químicos dentro de um contexto social, histórico e cultural.
Segundo Zitkoski e Mello (2002, p. 114), "a racionalidade técnico-científica, que (ainda) fundamenta os cursos universitários é o grande entrave para que ocorra uma transição paradigmática na cultura pedagógica contemporânea, à semelhança do que Freire propõe na lógica dialético-problematizadora dos saberes socioculturais".

Conforme aponta Maldaner (2000), apesar da crescente convicção entre os professores universitários responsáveis pela formação específica e entre os pesquisadores educacionais de que não é possível formar bons professores a partir da fragmentação e da busca pelo acúmulo de conhecimentos teóricos específicos e pedagógicos desvinculados entre si e longe da realidade das escolas, os professores universitários ligados aos departamentos e institutos das chamadas ciências básicas mantêm a convicção de que basta uma boa formação científica básica para preparar bons professores para o ensino médio, a ponto de os professores da formação pedagógica percebem a falta de uma visão clara e mais consistente dos conteúdos específicos, por parte dos licenciandos, de tal maneira que lhes permita uma reelaboração pedagógica, tornando-os disponíveis e adequados à aprendizagem das crianças e adolescentes.

Rosa (2004), por sua vez, observa a racionalidade técnica e descontextualizada ao descrever que na graduação as disciplinas são estruturadas dividindo o conhecimento químico em teórico e prático. O conhecimento teórico é desenvolvido e verificado pela resolução de exercícios; o prático, por meio de roteiros experimentais preestabelecidos, mecânicos, organizados passo a passo, que não lembram uma investigação $e$ primam pela eficiência, rendimento e êxito.

Conforme destacam Silva e Schnetzler (2005), além da dicotomia entre teoria e prática e conhecimentos específicos e pedagógicos, existem outras variáveis que contribuem para a pouca eficiência das licenciaturas. Para as autoras, a pouca efetividade é gerada, por um lado, pelos fatores institucionais e organizacionais; por outro, pelo próprio processo de constituição do professor, marcado por imagens sedimentadas nas vi- 
vências, forjadas a partir dos "outros" que fazem parte do seu território circundante e pelos encontros que a vida lhes proporciona, a formação ambiental.

Para superar esses obstáculos, Maldaner (2000) defende a formação inicial do professor, especificamente o professor de Química, baseada na reflexão proposta por Shön.

A proposta de formação reflexiva também é destaque nos documentos de ordem legal, conforme, por exemplo, o Parecer CNE/CES n ${ }^{\circ} 1.303$, de 6 de novembro de 2001, e a Resolução CNE/CES n ${ }^{\circ} 08$, de 11 de março de 2002, que tratam especificamente da formação do bacharel e do licenciado em Química.

\section{As aulas experimentais na Licenciatura em Química}

Atentos a Maar (2004), observamos que a utilização do laboratório de Química como instrumento didático nas universidades é feita há mais de duzentos anos. Apesar disso, Grandini e Grandini (2004) ressaltam que os estudos com fins pedagógicos e curriculares acerca do laboratório didático datam da década de 1960, abordando o uso do laboratório tanto na educação básica quanto na superior.

No tocante ao ensino superior, é clara a concepção da importância do laboratório e das aulas experimentais na formação inicial dos licenciandos em Ciências, tanto por parte dos professores quanto dos alunos. À luz dessa importância, as discussões que abordam o tema tratam do laboratório como ferramenta para: entrar em contato de modo mais "concreto" com a teoria ensinada em sala; alicerçar o conhecimento científico; dotar o licenciando de conhecimento técnico específico para atuação em laboratório; propiciar a construção de um ambiente motivador, agradável, estimulante e rico em situações novas e desafiadoras; estimular a capacidade ativa dos alunos. Destaca-se, contudo, que grande parte das aulas experimentais realizadas na graduação tem caráter de comprovação das teorias, não qualificando pedagogicamente os licenciandos para o desenvolvimento de aulas experimentais no nível médio (MALDANER, 2000; THOMAZ, 2000; GALIAZZI E GONÇALVES, 2004; GRANDINI E GRANDINI, 2004; NAVARRO et al, 2005; MACHADO E MÓL, 2008).

Grandini e Grandini (2004) apontam que as aulas experimentais e o processo de ensino-aprendizagem em relação aos objetivos do laboratório didático no nível superior, e como consequência a formação inicial que irão prestar aos licenciandos, comumente são norteados por duas linhas: a primeira defende que as aulas experimentais são necessárias para sedimentar os conceitos expostos nas aulas teóricas; a segunda defende que o alvo das aulas experimentais deve ser a obtenção e a análise de dados, considerando a teoria aprendida.

A linha seguida pelos professores é direcionada a partir de três vertentes para condução das aulas experimentais: a investigativa, a ilustrativa, $e$ a demonstrativa.

A experimentação investigativa é aquela empregada antes da discussão de conceitos e visa obter informações que alicercem a discussão, as explicações e a reflexão sobre a prática e os resultados, de modo tal que os alunos compreendam e construam não só os conceitos desejados como observem as diferentes formas de pensar e falar sobre o mundo por meio da ciência, sendo sua condução mais exigente e demandando mais tempo.

A experimentação ilustrativa geralmente é utilizada para demonstrar conceitos discutidos anteriormente, reforçando as teorias já estudadas, sendo desenvolvida sem muita problematização e com pouca ou nenhuma discussão sobre os resultados. Vê-se, assim, que a experimentação ilustrativa é mais fácil de ser conduzida do que a investigativa, o que a torna mais difundida tanto nos laboratórios dos cursos de formação inicial das universidades quanto nos laboratórios das escolas de educação básica.

$\mathrm{Na}$ experimentação demonstrativa, também denominada demonstração prática, os experimentos são realizados pelo professor e os alunos não podem intervir. Essa opção pode ser utilizada quando houver pouca disponibilidade de material, vidrarias e reagentes ou quando envolver o uso de reagentes perigosos. 
Todavia, independente da vertente ou da linha, Thomaz (2000) ressalta que as atividades e os objetivos das aulas experimentais estão fortemente centrados apenas nos conteúdos. Tal ênfase se deve, conforme Galiazzi e Gonçalves (2004), à formação pedagógica dos professores universitários adquirida por reprodução das ações de seus professores. Esta prima por uma formação conteudista, tácita, fragmentada e resistente à mudança por ser pouco refletida e fracamente fundamentada pedagogicamente, dada sua origem na formação ambiental.

Devido ao direcionamento das aulas experimentais aos conteúdos, são diversos os argumentos que ressaltam não só a carência da formação pedagógica dos licenciandos em ciências, mas a utilização do laboratório e das aulas experimentais na formação inicial como atividade intuitiva, reducionista, mecânica, empírica, não investigativa, não problematizadora e reprodutivista, na qual se busca comprovar a teoria centrando os objetivos do laboratório nos conteúdos e fortalecendo a visão da ciência como neutra, fazendo com que não se atendam às características formativas necessárias aos licenciandos para o desenvolvimento didático do laboratório no magistério de nível médio.

Como ressalta Schnetzler (apud MALDANER, 2000, p. 55), o uso dos experimentos na universidade prima pelo fortalecimento dos conteúdos e comprovação das teorias, seguindo um modelo de experimentação em que a aula teórica apenas é dada de outra maneira, com a finalidade de facilitar a explanação do assunto, de tornar a aula menos cansativa, de dispor e utilizar uma forma de memorizar melhor o conteúdo, em que se enfatiza a técnica na manipulação e utilização dos equipamentos e vidrarias, tornando as aulas experimentais mecânicas e não reflexivas.

Navarro et al (2005) destacam ainda outro ponto crucial à execução das aulas experimentais nas universidades e que acaba contribuindo para a ênfase na racionalidade técnica durante os experimentos: o pouco tempo disponível para a aula.

Machado e Mól (2008), por sua vez, destacam que no nível médio os professores não utilizam a ex- perimentação com a frequência que gostariam porque não desenvolveram um bom domínio de laboratório durante a formação inicial. Segundo Maldaner (2000), o aproveitamento do espaço laboratorial de Química disponível nas escolas ou a adaptação de salas ou experimentos não ocorre adequadamente devido à deficiência da preparação inicial dos professores nas seguintes situações:

- dentro das grandes universidades ou faculdades, não pela fragilidade na preparação técnica específica para atuação em laboratórios de Química, mas devido à carência profissional pedagógica para atuar em laboratórios de ensino e dentro das realidades das escolas;

- nas pequenas faculdades, além da carência da parte pedagógica, a formação pode ocorrer até mesmo sem que o professor desenvolva a preparação técnica para atuar em laboratórios.

É importante ressaltar que o Parecer $\mathrm{CNE} /$ CES n ${ }^{\circ} 1.303 / 01$, que trata das Diretrizes Curriculares Nacionais para os Cursos de Química, propõe que o licenciando tenha preparação adequada à aplicação pedagógica do conhecimento e experiências de Química e de áreas afins na atuação profissional como educador no ensino fundamental e médio. Para tanto, ainda durante sua formação inicial, o licenciando deve desenvolver habilidades e competências em relação ao ensino que lhe deem condições de saber trabalhar em laboratório e saber usar a experimentação em Química como recurso didático. Para tanto, é necessário que os professores das universidades compreendam que a experimentação que simplesmente comprova a teoria não é suficiente para preparar os licenciandos para o desenvolvimento de experimentos nas escolas, pois a experimentação na educação básica visa, além da compreensão do conteúdo, à compreensão dos fenômenos naturais, do cotidiano, das questões políticas, sociais e ambientais, demonstrando a evolução do conhecimento científico como algo dentro de uma realidade sócio-histórica em constante transformação. 


\section{O curso e as aulas experimentais da Li- cenciatura em Química a Distância da UFRN}

A licenciatura em Química ofertada a distância pela Universidade Federal do Rio Grande do Norte (UFRN) teve início no ano de 2006. A primeira turma de formandos concluiu os componentes curriculares necessários à formação inicial no final do primeiro semestre de 2010, sendo a primeira turma a concluir um curso de licenciatura em Química a distância no País.

Atentos ao Parecer CNE/CES n ${ }^{\circ} 1.303$, de 6 de novembro de 2001, e à Resolução CNE/CES n ${ }^{\circ} 08$, de 11 de março de 2002, a Licenciatura em Química a Distância da UFRN tem como proposta a preparação de um licenciado em Química com formação generalista, mas sólida e abrangente em conteúdos dos diversos campos da Química, com preparação para a aplicação pedagógica do conhecimento e das experiências de Química e de áreas afins na atuação profissional como educador no nível fundamental e médio.

Para tanto, se faz necessária a preparação inicial de um licenciado que tenha domínio das técnicas básicas de utilização de laboratórios, que saiba trabalhar em laboratório e saiba usar a experimentação em Química como recurso didático, bem como usar os procedimentos necessários de primeiros socorros, nos casos dos acidentes mais comuns em laboratórios de Química.

A partir dessa perspectiva, propõe-se que o licenciado tenha uma visão crítica com relação ao papel social da Ciência e à sua natureza epistemológica, compreendendo o processo histórico-social de sua construção, reconhecendo a Química como uma construção humana e compreendendo os aspectos históricos de sua produção e suas relações com o contexto cultural, socioeconômico e político, atento à compreensão dos conceitos, leis e princípios da Química.

Para atender essas prerrogativas, o curso é organizado em módulos semestrais, na busca pela integração entre os conteúdos de Química e correlações entre a Química e áreas afins, com destaque para Matemática, Física e Educação, objetivando a interdisciplinaridade, a partir dos conteúdos básicos, conteúdos específicos, estágios e atividades complementares.

Sob essa perspectiva, propõe-se que as aulas experimentais almejem não só a compreensão dos conceitos químicos, mas a inter-relação com os conteúdos procedimentais e atitudinais, a compreensão da ciência química como construção humana em constante transformação, a relação com os demais componentes curriculares e com os aspectos ambientais e sociais que envolvem a Química.

Atentos a essa proposta, vemos a busca por um curso que anseia uma formação reflexiva, em que as aulas experimentais busquem interagir com os conhecimentos específicos teóricos, sem apenas limitar-se à comprovação da teoria pela prática, estando esses conhecimentos teóricos em interação com os pedagógicos.

O curso disponibiliza aos licenciandos seis componentes curriculares de aulas experimentais, conforme disposto no Quadro 1.

As aulas experimentais envolvem momentos presenciais dos licenciandos no curso para desenvolvimento dessas aulas, propostas em cada componente curricular. É importante destacar que nem todas as aulas das disciplinas experimentais ocorrem no laboratório; algumas são apenas abordagens teóricas dos conhecimentos químicos.

Quadro 1: Componentes curriculares experimentais na licenciatura da UFRN

\begin{tabular}{|c|c|}
\hline Componente curricular experimental & Semestre no qual é ofertada a disciplina \\
\hline Medidas e transformações químicas & $2^{\circ}$ \\
\hline Vivenciando a química ambiental & $6^{\circ}$ \\
\hline Manipulação de compostos orgânicos & $7^{\circ}$ \\
\hline Experimentos de termoquímica & $7^{\circ}$ \\
\hline Síntese de produtos naturais & $9^{\circ}$ \\
\hline Cinética experimental & $9^{\circ}$ \\
\hline
\end{tabular}

Fonte: Projeto político-pedagógico da licenciatura em Química EaD da UFRN. 
As aulas experimentais ocorrem nos laboratórios de ensino de Química das Universidades e Faculdades com as quais a UFRN possui convênio ou em laboratórios adaptados, quando não há no polo do curso um espaço específico preexistente. As aulas experimentais também ocorrem nos laboratórios de ensino de Química da própria UFRN. Em todos os casos, as aulas experimentais são aplicadas pelos tutores de laboratório.

\section{Metodologia}

Este trabalho, de natureza qualitativa, trata de recortes de estudos de caso registrados em diário de bordo no decorrer das aulas experimentais desenvolvidas no laboratório de ensino de uma das universidades conveniadas com a UFRN, no período de 2008 a 2010, conforme Quadro 2.

Quadro 2: Período de acompanhamento dos componentes curriculares experimentais

\begin{tabular}{|c|c|}
\hline Componente curricular experimental & Período do registro das observações \\
\hline Vivenciando a Química ambiental & 2008.2 \\
\hline Manipulação de compostos orgânicos & 2009.1 \\
\hline Experimentos de Termoquímica & 2009.1 \\
\hline Síntese de produtos naturais & 2010.1 \\
\hline Cinética experimental & 2010.1 \\
\hline
\end{tabular}

Os registros envolveram duas etapas, a saber:

$1^{\mathrm{a}}$ - leitura e análise das aulas experimentais propostas em cada disciplina;

$2^{\mathrm{a}}$ - análise do desenvolvimento das aulas orientadas pelo tutor de laboratório.

Na primeira etapa, as aulas foram analisadas sob a proposta de Lüdke e André (1986), quando destacam que a leitura de material escrito envolve análise documental. As autoras consideram como documentos: leis, regulamentos, normas, pareceres, memorandos, jornais, revistas, discursos, dados estatísticos e arquivos escolares, entre outros materiais escritos que tragam informações e que possam ser usados como fonte para a pesquisa em andamento. Elas destacam que os documentos constituem fonte poderosa de onde podem ser retiradas evidências que fundamentem afirmações $e$ declarações do pesquisador.

A leitura de documentos envolve o que é denominado análise documental. Com essa análise, busca-se identificar informações factuais nos documentos a partir do levantamento de questões ou hipóteses importantes, sendo possível complementar informações obtidas com outras técnicas de coleta de dados, ratificando ou validando essas informações.

A segunda etapa envolveu os registros no diário de bordo de como o tutor desenvolvia as aulas experimentais, quais discussões eram feitas, como as aulas transcorriam, os problemas enfrentados durante a execução das práticas.

A junção dessas etapas objetiva verificar as contribuições e as lacunas na formação dos licenciandos a partir do desenvolvimento das aulas experimentais.

\section{Resultados}

Os resultados da leitura e análise das aulas experimentais propostas pelos docentes e dos procedimentos adotados pelo tutor de laboratório para o desenvolvimento dessas aulas práticas frente à proposta de formação de professores na $\mathrm{Li}$ cenciatura em Química a Distância da UFRN estão descritos a seguir.

Para tornar a leitura mais didática, os resultados foram divididos em dois grupos, atentos ao descrito na metodologia. 
7.1. Leitura e análise das aulas experimentais propostas em cada disciplina

Esta etapa tratou de um estudo das aulas experimentais propostas de 2008 a 2010, com vistas a buscar relações entre a proposta de formação e utilização do laboratório na licenciatura a distância da UFRN e o elaborado pelos professores nas aulas das disciplinas experimentais.

A leitura das aulas demonstrou que os experimentos estão intimamente ligados aos conteúdos ofertados em cada uma das disciplinas. Observamos também que as aulas costumam ser reproduções de experimentos clássicos e já consagrados em diversas literaturas específicas; quando isso não ocorria, as propostas experimentais envolviam o uso de materiais de fácil aquisição em supermercado. $\mathrm{O}$ material escrito possui linguagem simples, clara e sucinta, deixando evidentes os objetivos almejados em cada aula. As aulas possuem um pré-laboratório, onde se orientam e se propõem atividades que facilitam a compreensão dos experimentos, e um pós-laboratório, cujo objetivo é complementar e fortalecer os assuntos abordados na aula em questão.

Vemos, a partir do material escrito, a importância do conteúdo voltado ao conhecimento específico, isto é, ao conhecimento em Química; todavia, é praticamente inexistente ou muito discreta a relação do conhecimento químico com o pedagógico e com a transposição didática daqueles experimentos para as escolas de Educação Básica.

Salvo algumas breves passagens ou atividades de pesquisas pré e pós-laboratório, não há relação dos experimentos propostos com o cotidiano dos alunos, com questões ambientais, sociais, políticas e econômicas, com a compreensão dos fenômenos naturais nem com as dificuldades e obstáculos que os licenciandos encontrarão para o desenvolvimento e adaptação daquelas práticas nas escolas; quando ocorria essa relação, a proposta era muito discreta, não ficando clara essa ideia aos licenciandos, tampouco como utilizá-la e discuti-la nas escolas, restringindo tanto a experimentação quanto a abordagem teórica aos aspectos conceituais.
As práticas propostas nas aulas são orientadas pela experimentação ilustrativa, uma vez que primam pela comprovação de conceitos discutidos anteriormente, reforçando as teorias já estudadas, sendo desenvolvidas sem muita problematização e com pouca ou nenhuma discussão sobre os resultados.

Sob essa perspectiva, as aulas experimentais propostas contribuem fortemente para a formação alicerçada na racionalidade técnica, haja vista a forte base conceitual com os experimentos, a estrutura dos roteiros - que é pouco reflexiva, mecânica e indutiva -, a inexistência da relação entre os conhecimentos químicos e pedagógicos com base na experimentação, a falta de discussões acerca da transposição didática das práticas aos laboratórios nas escolas.

\subsection{Análise do desenvolvimento das aulas orientadas pelo tutor de laboratório}

Esta etapa tratou do registro em diário de bordo das aulas experimentais desenvolvidas pelo tutor de 2008 a 2010, com vistas a buscar relações entre a proposta de formação e utilização do laboratório na licenciatura a distância da UFRN e o efetuado pelo tutor nas aulas das disciplinas experimentais. Para tanto, procedeu-se ao registro das discussões e dos procedimentos adotados pelo tutor quando do desenvolvimento das aulas experimentais.

Observamos que o tutor sempre começava as aulas experimentais discutindo com os alunos o que seria feito no experimento, apresentava os objetivos da aula, demonstrava os equipamentos e vidrarias que seriam utilizados, mas não se aprofundava em detalhes sobre eles. Eventualmente fazia uma breve explanação da relação dos experimentos com a indústria química, com questões ambientais e econômicas, principalmente se no pré ou pós-laboratório tal procedimento fosse adotado ou proposto aos alunos como atividade complementar. Todavia, raramente verificava, aluno por aluno, se cada um havia feito a atividade pré-laboratorial. Orientado pelos professores que elaboravam as aulas experimentais, 
formava grupos com 3 ou 4 alunos, formados sempre pelos mesmos alunos, e iniciava a experimentação. As aulas experimentais ocorriam sempre aos sábados, a pedido dos alunos.

Normalmente os alunos já encontravam as vidrarias, equipamentos, soluções e reagentes separados para cada grupo. Esse procedimento era feito com o objetivo de dispor aos licenciandos um tempo maior para a execução do experimento e discussões sobre os resultados. Observamos, contudo, que esse procedimento era menos frequente quando mais de duas disciplinas faziam experimentos ao mesmo tempo. Verificamos isso, por exemplo, no semestre 2010.1, quando, além da oferta das duas disciplinas do período para os alunos regulares, também foram ofertadas outras duas disciplinas experimentais para os alunos que estavam atrasados, somando quatro disciplinas experimentais cujas aulas experimentais poderiam ocorrer no mesmo dia, devido ao choque de horário com a disciplina Estágio Supervisionado, que também é presencial e que tinha alguns alunos em comum com os componentes curriculares de laboratório, forçando mudanças no cronograma de experimentos proposto pela UFRN.

Nesses casos, o tutor não distribuía os materiais e reagentes por grupos; deixava-os juntos numa única bancada, onde os grupos pegavam o que precisavam para aquele momento do experimento, devolvendo-os o mais breve possível, já que outros grupos poderiam precisar dos mesmos materiais e reagentes no experimento de outra disciplina.

Vemos, com esse procedimento, os problemas relacionados com a carência de material que o laboratório disponibilizava. É necessário destacar que estamos acompanhando as aulas experimentais dentro do laboratório de ensino de Química de uma universidade cuja estrutura deveria oferecer de antemão todos os equipamentos, vidrarias, reagentes e soluções que provavelmente seriam necessários para aqueles experimentos. Podemos destacar isso por pelo menos dois motivos:

1. porque as aulas experimentais desenvolvidas envolviam, na sua maioria, reproduções de ex- perimentos clássicos, bastante difundidos na literatura específica e cuja proposta costuma ser comum nas universidades, o que pressupóe a existência do material na universidade conveniada com a UFRN;

2. uma vez que havia convênio entre as universidades, a UFRN supostamente enviara reagentes e vidrarias necessários ao desenvolvimento das aulas experimentais previstas, tanto para repor aqueles da universidade que foram utilizados quanto para disponibilizar aqueles em falta ou em pouca quantidade.

No decorrer da aula experimental, o tutor acompanhava os grupos orientando e corrigindo os procedimentos ligados à manipulação das vidrarias $e$ equipamentos, tirando dúvidas acerca do que se observava no experimento, registrando no quadro os resultados observados por cada grupo, eventualmente fazendo alguma abordagem acerca da experimentação nas escolas.

Todavia, outro ponto negativo observado quando do desenvolvimento dos experimentos das quatro disciplinas ao mesmo tempo era a redução da aula à simples execução do roteiro proposto. Como as disciplinas tinham objetivos distintos, com roteiros e experimentos ora maiores, ora menores, o tutor costumava reduzir a aula experimental ao cumprimento do proposto no roteiro, objetivando a obtenção dos resultados para posterior elaboração de relatórios e respostas ao pós-laboratório pelos licenciandos. Destacamos, entretanto, que para conseguir acompanhar as quatro disciplinas ao mesmo tempo o tutor pedia auxílio a outros dois colegas, que, apesar de serem graduados e mestres em Química, também reduziam a experimentação à mera execução do roteiro. Além do apoio dos colegas, o tutor de laboratório era auxiliado voluntariamente em uma das matérias por um aluno que estava repetindo a disciplina e que já conhecia os procedimentos necessários ao desenvolvimento dos experimentos em questão. Em todos os casos, mais 
uma vez, vemos a forte influência da racionalidade técnica na formação dos licenciandos, já que os experimentos eram feitos sem discussões e reflexões acerca da experimentação nas escolas, sem reflexões sobre os fenômenos naturais, e sim de modo mecânico, empírico e reprodutivista.

Ao final das aulas experimentais, independentemente da quantidade de disciplinas, o tutor discutia os resultados obtidos e resolvia com os alunos algumas questões que relacionavam a aula e o pós-laboratório, mas raramente discutia com profundidade a aplicação daqueles experimentos nas escolas, mesmo quando estava desenvolvendo a experimentação de apenas uma disciplina.

À luz dessas observações, vemos que o acompanhamento que o tutor presta nas aulas experimentais também contribui fortemente para a formação alicerçada na racionalidade técnica.

\section{Considerações finais}

A partir desses recortes, vemos que as aulas experimentais propostas na Licenciatura em Química a Distância da UFRN não conseguiram ainda atender à proposta de formação reflexiva, segundo discursa, entre outros estudiosos, Shön. Isso porque foram elaboradas primando pelo desenvolvimento do experimento de modo mecânico, trazendo pouca ou nenhuma relação com o cotidiano escolar, com questões sociais, políticas, ambientais e econômicas, com a evolução científica e humana, limitando-se aos aspectos conceituais e procedimentais do conhecimento químico, fortalecendo apenas os conhecimentos necessários à formação do professor dessa ciência.

Essa propriedade não é observada apenas na organização do material que os licenciandos recebem; também é observada na atuação do tutor de laboratório, principalmente quando ele precisa acompanhar concomitantemente os alunos em experimentos de diferentes disciplinas. Destacamos que a atuação do tutor nas aulas experimentais é fruto de uma formação alicerçada na racionalidade técnica, sendo essa sua principal referência de docência em laboratório, mas observamos também momentos em que o tutor toma como base a formação ambiental, quando cita que adota como modelos alguns procedimentos observados nos seus ex-professores.

Sob essa perspectiva, vemos que as práticas desenvolvidas que envolvem a experimentação ilustrativa não contribuem para o desenvolvimento dos conhecimentos pedagógicos indispensáveis à proposta reflexiva de formação do licenciando, mas contribuem fortemente para a formação de origem técnica, já que estão direcionadas mais fortemente aos conhecimentos de Química.

Vemos, assim, a necessidade de disponibilizar capacitações mais direcionadas à formação reflexiva ao tutor de laboratório e de aperfeiçoar a proposta das aulas experimentais para dispor aos licenciandos - futuros professores na Educação Básica - condições de desenvolver com plenitude e atentos aos documentos legais e estudos acadêmicos aulas experimentais nas escolas, contribuindo para uma melhor compreensão dos conhecimentos químicos no cotidiano das pessoas e na evolução e transformação da sociedade.

\section{Referências}

BRASIL. Lei n ${ }^{\circ} 10.172$, de 9 de janeiro de 2001. Aprova o plano nacional de educação e dá outras providências. Diário Oficial da União, Poder Executivo, Brasília, 10 de janeiro de 2001.

. Parecer $\mathrm{CNE} / \mathrm{CP} \mathrm{n}^{\circ}$ 9, de 8 de maio de 2001. Trata das diretrizes curriculares nacionais para a formação de professores da educação básica, em nível superior, curso de licenciatura, de graduação plena. Diário Oficial da União, Poder Executivo, Brasília, 18 de janeiro de 2002. 
. Parecer CNE/CES n 1.303, de 6 de novembro de 2001. Diretrizes curriculares nacionais para cursos de Química, bacharelado e licenciatura. Diário Oficial da União, Poder Executivo, Brasília, 7 de dezembro de 2001.

Resolução CNE/CP n ${ }^{\circ}$, de 18 de fevereiro de 2002. Institui as diretrizes curriculares nacionais para a formação de professores da Educação Básica, em nível superior, curso de licenciatura, de graduação plena. Diário Oficial da União, Poder Executivo, Brasília, 4 de março de 2002.

Resolução $\mathrm{CNE} / \mathrm{CES} n^{\circ}$ 8, de 11 de março de 2002. Estabelece as diretrizes curriculares para os cursos de bacharelado e licenciatura em Química. Diário Oficial da União, Brasília, 26 de março de 2002.

CARVALHO, Ana Maria Pessoa de; GIL-PÉREZ, Daniel. Formação de professores de ciências. 2. ed. São Paulo: Cortez, 1995. v. 26. 119 p. (Questões da nossa época).

FÁVERO, Osmar. A educação no congresso constituinte de 1966-67: contrapontos. In: constituintes brasileiras: 1823-1988. 3. ed. São Paulo: Autores Associados, 2005. p. 241-253.

A educação nas

GALIAZZI, Maria do Carmo; GONÇALVES, Fábio Peres. A natureza pedagógica da experimentação: uma pesquisa na licenciatura em Química. Química Nova. v. 27, n. 2, p. 326-331, 2004.

GRANDINI, Nádia Alves; GRANDINI, Carlos Roberto. Os objetivos do laboratório didático na visão dos alunos do curso de licenciatura em Física da UNESP-Bauru. Revista Brasileira de Ensino de Física. v. 26, n. 3, p. 251-256, 2004.

LÜDKE, Menga; ANDRÉ, Marli Eliza D. A. Pesquisa em educação: abordagens qualitativas. São Paulo: EPU, 1986. p. 35-43.

MAAR, Juergen Heinrich. Aspectos históricos do ensino superior de química. Scientae Studia. São Paulo, v. 2, n. 1, p. 33-84, 2004.

MACHADO, Patrícia Fernandes Lootens; MÓL, Gerson de Souza. Experimentando Química com segurança. Química Nova na Escola. n. 27, p. 57-60, 2008.

MALDANER, Otávio Aloísio. A formação inicial e continuada de professores de química: professor pesquisador. Ijuí: Ed. Unijuí, 2000. 429 p. (Coleção educação em química).

MIZUKAMI, Maria da Graça Nicoletti et al. Escola e aprendizagem da docência: processos de investigação e formação. São Carlos: EdUFSCar, 2002. 203 p.

NAVARRO, Marcelo et al. Atualizando a Química Orgânica experimental da licenciatura. Química Nova. v. 28, n. 6, p. 1.111-1.115, 2005.

NÓVOA, António. O passado e o presente dos professores. In: (org.). Profissão professor. Porto: Porto, 1995. p. 9-29.

ROSA, Maria Inês Petrucci. Investigação e ensino: articulação e possibilidades na formação de professores de ciências. Ijuí: Ed. Unijuí, 2004. p. 16-25. (Coleção educação em Química).

SHÖN, Donald. Formar professores como profissionais reflexivos. In: NÓVOA, António (ed.). Os professores e sua formação. Lisboa: Dom Quixote, 1992. p. 77-91.

SILVA, Rejane Maria Ghisolfi; SCHNETZLER, Roseli Pacheco. Constituição de professores universitários de disciplinas sobre ensino de Química. Química Nova. v. 28, n. 6, p. 1.123-1.133, 2005. 
TANURI, Leonor Maria. História da formação de professores. Revista Brasileira de Educação: Anped. Rio de Janeiro: Autores Associados, n. 14, p. 61-88, maio/ago. 2000.

THOMAZ, Marília Fernandez. A experimentação e a formação de professores de ciências: uma reflexão. Caderno Cat. de Ensino de Física. v. 17, n. 3, p. 360-369, dez. 2000.

ZITKOSKI, Jaime José; MELLO, Reynaldo Irapuã Camargo. Formação de professores: desafio para as universidades no contexto da educação. In: MELLO, Reynaldo Irapuã Camargo (org.). Pesquisa e formação de professores. Cruz Alta: Centro Gráfico Unicruz, 2002. p. 109-119. 